Nuntius Antiquus, Belo Horizonte, v. 12, n. 2, p. 201-224, 2016

\title{
Heroísmo ma non troppo: o paradigma deficitário de Quéreas e Jasão
}

\author{
Heroism ma non troppo: \\ the deficitary paradigm of Chaereas and Jason
}

Pedro Barbieri Antunes

Universidade de São Paulo

São Paulo, São Paulo / Brasil

pedrobarbieri.antunes@gmail.com

Resumo: Adotando o argumento de um processo de transformação pelo qual Quéreas passa ao demonstrar um caráter mais forte nos dois últimos livros de Quéreas e Calírroe, pretendo explorar aqui os momentos de insegurança e hesitação que esse personagem apresenta nos seis primeiros livros do romance e como isso se encaixa no seu programa heroico. Para tanto, como termo de comparação, apresento a já bastante explorada figuração do êtthos de Jasão e busco encontrar nele alguns germes da conduta de Quéreas, de modo a rastrear uma espécie de árvore genealógica desse tipo de caracterização, em alguns pontos avesso ao código tradicional homérico.

Palavras-chave: Cáriton; Quéreas e Calírroe; Apolônio de Rodes; Argonáuticas; Quéreas; Jasão.

Abstract: Adopting the argument of a transformation process by which Chaereas undergoes, demonstrating a stronger character in the last two books of Chaereas and Callirhoe, I intend to explore the moments of uncertainty and hesitation that this character has in the first six books of this novel and how it fits in his heroic program. Therefore, as a comparison, I present the already well explored representation of Jason's ethos and seek to find in it some germs of Chaereas' conduct in order to trace a sort of family tree of this type of characterization, in some aspects a counterpoint to the traditional Homeric code. Keywords: Chariton; Chaereas and Callirhoe; Apollonius of Rhodes; Argonautica; Chaereas; Jason. 
Recebido em 28 de julho de 2016. Aprovado em 1 de dezembro de 2016.

\section{Introdução}

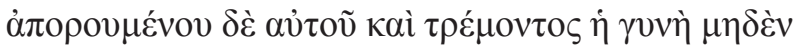

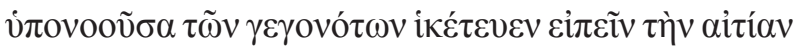

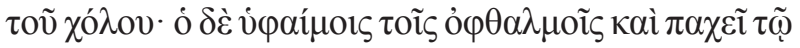

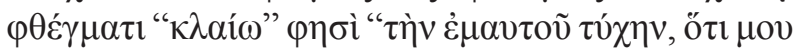

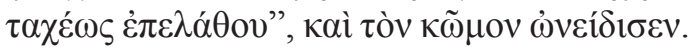

Porque ele estava atônito e tremia sem parar, sua esposa, que não suspeitava do acontecido, suplicoulhe que dissesse a causa da ira. E ele, com os olhos injetados e a voz grave, disse: "Choro a minha sorte, porque você me esqueceu bem rápido" - e a repreendeu pela festa. ${ }^{1}$ (CÁRITON, Quéreas e Calírroe, 1.3.5)

A primeira palavra de Quéreas em Quéreas e Calírroe $(Q \& C)$ é klaío, "choro" (1.3.5), o que, de certo modo, parece ser, se não programático de toda a conduta desse personagem, ao menos modelar no decorrer dos seis primeiros livros desse romance. A observação de uma "subjetividade masculina insegura" em Quéreas não é algo novo. ${ }^{2}$ Enquanto Calírroe parece estar constantemente sob os holofotes da narrativa (SMITH, 2007, p. 18), seja presencialmente, seja como um móbile erótico que conduz as dramatis personae, Quéreas, em um primeiro momento, não obstante faça parte do casal principal, apresenta uma conduta inicial oblíqua, que marca profundamente o seu estágio formativo antes de se firmar efetivamente como um herói praticamente épico e dotado de habilidades retóricas (HELMS, 1966, p. 28-29; HOLZBERG, 1995, p. 45; SMITH, 2007, p. 19; TEMMERMAN, 2009). Com efeito, podemos nos lembrar da passagem em que ele é descrito

\footnotetext{
${ }^{1}$ Todas as traduções do romance são de Adriane Duarte (no prelo).

${ }^{2}$ Cf. Smith (2007, p. 18-19), que apresenta um breve status quaestionis a respeito da caracterização de Quéreas.
} 
como "um rapaz formoso, superior a todos, como os Aquiles, Nireu, Hipólito, Alcibíades que escultores e pintores retratam" (1.1.3). Esse excerto nos permite pensar que Cáriton se posiciona como um escultor ou um pintor e o Aquiles que será feito de Quéreas não é algo dado desde início, in medias res, mas é exatamente um processo de criação, atualização e cristalização de um potencial aquileico. Enquanto Calírroe é bela $a b$ ovo e essa parece ser a sua característica que mais recebe atenção por parte do narrador (SCHMELING, 2005; HÄGG, 1983, p. 6), Quéreas é um personagem a ser esculpido. ${ }^{3}$ A representação de Calírroe é divina, ela sendo amiúde comparada a Afrodite, e é pautada na beleza, o que a torna axiologicamente uma personagem pronta; por outro lado, Quéreas é equiparado a heróis e humanos, dos quais um processo de formação concomitante a um estágio embrionário (e deficitário) em relação à expectativa heroica não deveria surpreender.

Contudo, pode-se argumentar certa simetria entre Calírroe e Quéreas, pois podemos ler a avaliação inicial de ambos como pautada no critério comum da beleza ou da fidelidade. Em um artigo muito influente, Konstan inclusive propõe uma análise de ambas as personagens chegando a entrever certa equivalência entre elas, passando por diversos expedientes compensatórios (KONSTAN, 1994, p. 15-18). Não obstante, é possível constatar também uma disparidade essencial na construção de ambas as personagens, ${ }^{4}$ pois o parâmetro de avaliação comum para elas não precisa ser necessariamente a beleza compartilhada por ambos ou o

\footnotetext{
${ }^{3}$ Noto, entretanto, que, em conferência pessoal, Adriane Duarte me apontou a possibilidade de que a comparação com a escultura sirva a ambos, pois a aproximação de Calírroe à "Afrodite Donzela" (1.1.2) pode ter como pano de fundo um tipo específico de representação material da deusa nos monumentos de Afrodísias. O argumento é atraente e pode-se inclusive frisar que, na mesma altura do texto, ela é descrita como ágalma, "estátua". Todavia, persisto na minha colocação por uma perspectiva narratológica: Calírroe apresenta uma tipologia interna constante, cujas oscilações resultam apenas das influências externas; Quéreas, por sua vez, apresenta tamanha variabilidade diante dos eventos que creio tratar-se de algo melhor explicado pelo parâmetro da formação, de um processo - do que ainda considero uma metáfora eficaz a sua representação como alguém a ser esculpido.

${ }^{4}$ Persigo esse argumento mais adiante, mas partes dele já estão formuladas em Temmerman (2014a).
} 
amor recíproco. ${ }^{5}$ Se notarmos que Quéreas não é avaliado unicamente dessa forma, ao passo que Calírroe o é, temos que essa classificação não é suficiente para entendermos o protagonista masculino. É preciso buscar outro critério. Com efeito, no decorrer do romance, como pretendo apresentar, Calírroe continua sendo completamente adequada para as únicas expectativas sociais que se tem dela, a sua forma física e a sua fidelidade, ${ }^{6}$ ao passo que Quéreas é, inicialmente, insuficiente e inadequado para o programa aquileico dentro do qual está inscrito. Se uma maior ênfase em uma postura ativa por parte de Calírroe e uma passivação do êthos de Quéreas garantem certo equilíbrio entre as duas personagens consideradas relativamente uma com respeito à outra, ainda assim, tomadas de forma absoluta e não interseccionada, ela é desenhada sem alteração, enquanto ele apresenta uma evidente mudança diacrônica. Logo, há uma assimetria no quesito da autoadequação: Calírroe está em dia com a sua beleza, mas Quéreas não está em dia com ser um herói.

A minha intenção é precisamente avaliar isto: não Quéreas em sua faceta militar, discursiva e quase homérica, ${ }^{7}$ mas, sim, esses momentos em que ele aparece subordinado às demais personagens e também aos seus próprios sentimentos. Trato aqui das fraquezas de Quéreas e, para entendê-las, proponho também um breve exame da representação de Jasão nas Argonáuticas.

\footnotetext{
${ }^{5}$ Como é abordado por Konstan (1994, p. 34-36). Daí o meu distanciamento aparente com o seu texto: proponho aqui uma assimetria porque a minha abordagem repousa em diferentes termos de análise que os dele. No que diz respeito à fidelidade que ambas partes demonstram, pode-se de fato argumentar uma simetria. No quesito da beleza, nota-se um common ground, mas, enquanto a coincidência é qualitativa, há uma patente diferença de grau quanto ao aspecto físico de cada personagem (TEMMERMAN, 2014b, p. 47: "Chaereas' beauty is said to surpass all other men's, but it nevertheless lacks the divine dimension of Callirhoe's"). No entanto, nenhum desses dois itens compõe a minha preocupação atual.

${ }^{6}$ Quanto ao seu casamento com Dionísio, o próprio Konstan (1994, p. 50-51) já faz uma ressalva apontando que, de qualquer forma, isso não necessariamente constituiria uma quebra no laço de lealdade, uma vez que o laço nunca é consumado, justificativa com a qual concordo.

${ }^{7}$ Para algumas leituras sobre esse lado de Quéreas, cf. Smith (2007, p. 87-94 e p. 199248); Temmerman, (2009, p. 253-261).
} 


\section{Protagonismo formal}

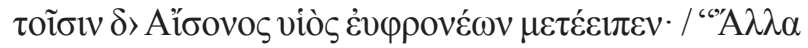

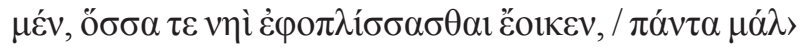

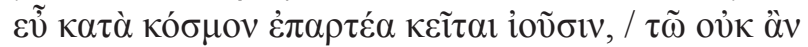

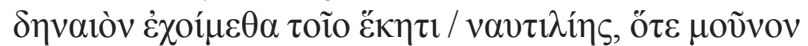

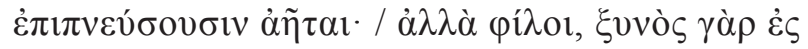

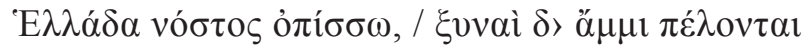

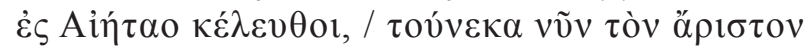

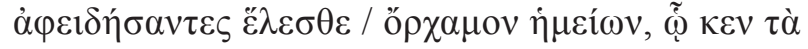

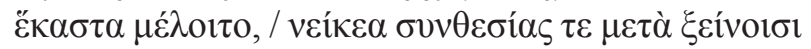

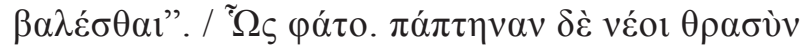

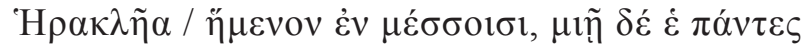

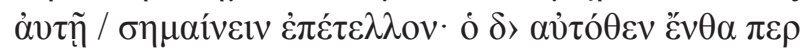

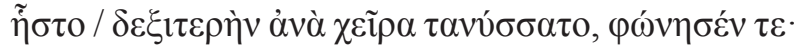

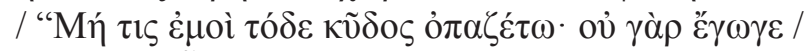

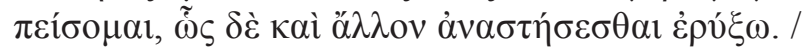

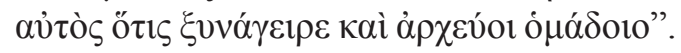

A eles o filho de Esão prudentemente disse: / "Parece que estão prontas as coisas para a nau / e tudo jaz preparado em boa ordem para partirmos, / por isso não nos reteríamos por muito tempo da / navegação, quando somente os ventos soprarem. / Mas, caros, é comum o retorno posterior à Hélade / e são comuns a nós as rotas até Eeta, / logo, não hesitando, escolhei agora o melhor / para ser nosso chefe, o qual se ocupará de cada coisa, / como realizar disputas e pactos com os estrangeiros". / Assim falou. Os jovens fitaram o corajoso Héracles / sentado no meio deles e todos, numa única e mesma voz, / exortavam-no a ser o chefe. Ele, no mesmo lugar onde estava / sentado, esticou a mão direita e disse: / "Que ninguém conceda a mim este renome, pois eu não / obedecerei e também impedirei um outro de se levantar. / Aquele que nos reuniu seja o nosso líder". ${ }^{8}$ (APOLÔNIO DE RODES, Argonáuticas, 1.331-47)

\footnotetext{
${ }^{8}$ As traduções das Argonáuticas são de Fernando Rodrigues Junior (2010).
} 
A passagem acima ilustra um momento bastante emblemático no épico de Apolônio. Jasão se posiciona esquivamente, talvez como uma captatio beneuolentiae, talvez por não se reconhecer digno do papel de líder. Não obstante o seu posicionamento, é sintomático que todos os tripulantes da nau Argo considerem inicialmente Héracles como o herói mais apto a comandá-los. Jasão não é a primeira opção, mas uma alternativa (BEYE, 1969, p. 40). Como no caso de Quéreas, o que podemos chamar de "fraqueza" em Jasão não é nenhuma novidade. ${ }^{9}$ Axiologicamente, portanto, Héracles seria a pessoa mais bem indicada para o papel. O que temos nas Argonáuticas, porém, é a conformação da decisão final dos tripulantes a uma escolha narrativa pré-determinada que de certo modo tenta justificar o protagonismo de Jasão. O que ele representa de pronto não corresponde ao que é reconhecido em ampla escala como o mais adequado para uma jornada heroica - reconhecimento esse representado pela primeira escolha dos tripulantes. Quando, após o catálogo de heróis, eles todos aparecem orbitando ao redor de Jasão (1.228-233), isso não se dá necessariamente em decorrência da liderança que ele representaria, mas talvez apenas por ele ser o motivo da congregação de heróis. O itinerário narrativo tenta ratificar a opção de Jasão como o centro da história mediante um mecanismo de inversão: ${ }^{10}$ Apolônio deliberadamente marginaliza Héracles no decorrer dos episódios, ${ }^{11}$ quando não simplesmente o trata de forma cômica. ${ }^{12}$ Com o subsequente abandono de Héracles ao final do primeiro livro das

\footnotetext{
${ }^{9}$ Para um panorama dessa recepção, cf. Rodrigues Junior (2010, p. 10-49).

${ }^{10}$ Denomino esse expediente como uma "inversão" pois, além de Héracles ser o primeiro escolhido como líder, não podemos esquecer que, na distribuição dos assentos na nau, mesmo após a tomada de liderança por Jasão, Héracles ainda assim recebe a posição central (1.396-7). Apolônio inverterá esse padrão, transmitindo a posição axial a quem antes estava de lado, no caso, Jasão.

${ }^{11}$ Héracles permanece na nau Argo à chegada dos heróis em Lemno (1.854-6). O mesmo acontece no episódio de Cízico (1.992-4).

${ }^{12}$ Refiro-me, por exemplo, a quando Héracles quebra o seu remo no caminho para a Mísia (1.1170-1), o que é já um indicativo da recusa desse tipo heroico realizada por Apolônio (BEYE, 1969, p. 44-45) - como logo apresentarei, Héracles é, ao mesmo tempo, o contraponto heroico que serve como contraste para Jasão $e$ o ensejo à reavaliação desse mesmo tertium comparationis. Desse último ponto, porém, não trato a fundo aqui; recomendo, para uma discussão mais detalhada: Lawall (1966); Beye (1969); Rodrigues Junior (2010).
} 
Argonáuticas, a narrativa definitivamente coage Jasão a um protagonismo que, em um primeiro momento, não se adequa às suas capacidades. ${ }^{13}$

A polarização heroica entre Héracles e Jasão se sustenta em um ponto muito simples: ela não é horizontal, no sentido de que cada qual já possuiria uma valência própria que poderia ser medida com a de seu "adversário"; o que ocorre, de fato, é uma polarização vertical, uma vez que Héracles é constantemente retratado como um herói já definido, de um vigor inabalável, ao passo que o heroísmo que testemunhamos em Jasão é embrionário, tímido, se não, por vezes, de todo ausente, dando lugar a uma consternação interna que se situa aquém de qualquer ação ou decisão. ${ }^{14} \mathrm{Em}$ Lemno, por exemplo, Jasão, como o líder formal dos mínios, toma a dianteira e vai ter com Hipsípile. Enquanto o herói se demora nessa parada e a partida é continuamente adiada, Héracles reprova tal atitude, apontando que, ao permaneceram ali, os mínios não completariam a sua tarefa e jamais receberiam glória, uma vez que se posicionariam aquém da ação - a jornada dos heróis não se cumpriria com "preces" (1.865-74). O foco inicial de Héracles na travessia é proporcional à hesitação de Jasão. ${ }^{15}$ Durante o primeiro livro, Héracles funciona como uma lembrança de orientação em meio à viagem orquestrada por Jasão. Além da obliquidade geral de Jasão, quando o herói de fato tenta tomar a dianteira, ele comete um erro, matando Cízico acidentalmente (1.1032-5), ${ }^{16} \mathrm{o}$ que evidencia ainda mais o quão pouco preparado para o seu papel de protagonista heroico ele parece estar - a reação dos personagens após o reconhecimento de seu equívoco é de lamento e muito próxima à postura reativa e lastimosa de Quéreas.

${ }^{13}$ Héracles é descrito, inclusive, como o "melhor de seus companheiros" (1.1284-6). Vale aqui também lembrar do discurso de Lico que lamenta a ausência de Héracles (2.774-5). Inicialmente, Jasão não consegue substituir a lacuna deixada pelo outro herói (cf. ainda 2.145-53).

${ }^{14}$ Para outros momentos que ilustram as atitudes de cada um dos heróis, cf. para Héracles: 1.989-1011; para Jasão, temos, por exemplo, as seguintes passagens (dentre as quais algumas serão tratadas em pormenor mais adiante): 1.462-71, 1.534-5, 1.133643, 2.409-10, 2.436-47, 2.610-37, 2.885-93.

${ }^{15}$ Em sua conversa com Tífis, por exemplo, fica evidente, mais uma vez, a postura insularizada de Jasão, quando trata de seu arrependimento em ter iniciado a expedição (2.610-37).

${ }^{16}$ Beye, 1969, p. 42; Rodrigues Junior, 2010, p. 11. 
À lateralidade e inadequação iniciais de Jasão correspondem aquelas de Quéreas. Como comparação, é possível trazer a passagem em que Quéreas é julgado pelo suposto assassinato de Calírroe:

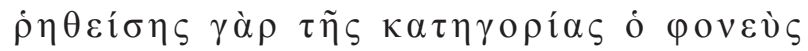

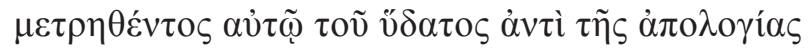

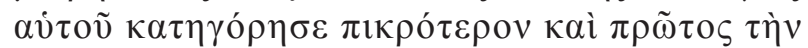

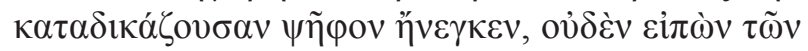

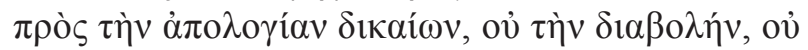

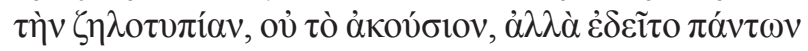

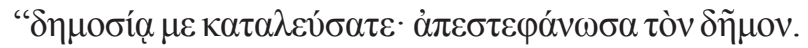

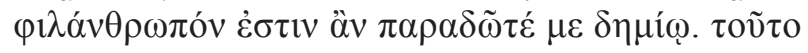

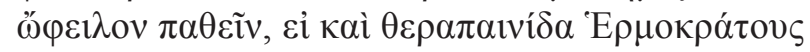

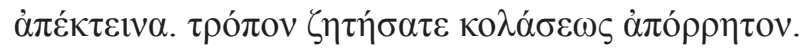

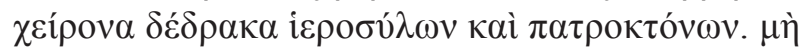

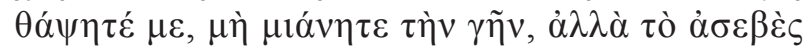

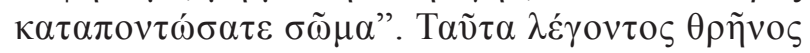

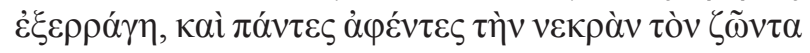

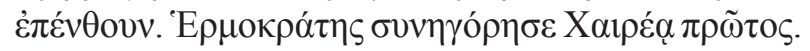

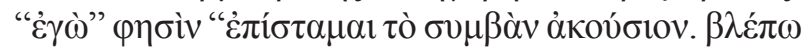

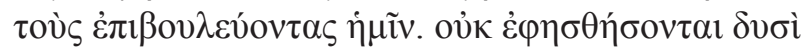

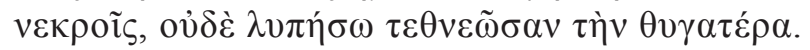

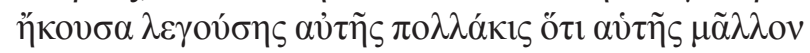

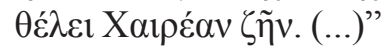

Depois do discurso de acusação, o assassino, quando seu tempo já corria, em vez de defesa, apresentou contra si acusação ainda mais dura e foi o primeiro a pedir a própria condenação, sem nada mencionar do que é atenuante em uma causa: nem calúnia, nem ciúme, nem o involuntário do ato, mas pedia a todos: "Lapidem-me à vista de todos. Privei o povo de sua coroa. É um ato de bondade, entregarem-me ao carrasco. Deveria incorrer nessa pena, caso tivesse matado uma escrava de Hermócrates. Busquem um modo de punição inaudito. Eu cometi um crime pior que sacrilégio e parricídio. Não me sepultem, não poluam este solo, mas atirem ao mar meu corpo maldito". Disse isso e o canto fúnebre eclodiu, todos 
deixaram a morta de lado e passaram a chorar o vivo. Hermócrates foi o primeiro a tomar a defesa de Quéreas, dizendo: "Eu sei que o ato foi involuntário. Estou vendo aqueles que tramaram contra nós. Não lhes darei a alegria de dois cadáveres, nem desgostarei a filha morta. Ouvi dela muitas vezes que preferia Quéreas vivo a ela mesma. (...)" (1.5.4-6)

Uma vez que a capacidade discursiva de Quéreas será analisada mais adiante, por enquanto vale notar apenas o que esse episódio simboliza. Ao tentar apoderar-se de sua própria vida, tomando uma decisão que, inclusive, poderia resultar na sua morte, Quéreas tem o seu desejo ignorado por Hermócrates, que, por ora, representa a faceta do poder exercida em toda a sua potência. Embebido em seus sentimentos, Quéreas ainda não possui o discernimento de justiça empregado por Hermócrates. O paralelo é evidente: Quéreas está para Jasão como Hermócrates para Héracles. Essa caracterização se estende a tal ponto que Quéreas considera a possibilidade de suicídio (1.6.1), motivo recorrente que marca a sua incapacidade de lidar com os fatos diretamente: as suas diversas tentativas de suicídio podem ser encaradas como uma resolução extrema e ensimesmada para as adversidades enfrentadas e, portanto, a redefinição de crises externas a um novo locus, aquém dos atos. ${ }^{17} \mathrm{O}$ protagonismo narrativo de Quéreas não encontra um reflexo na sua capacidade de gerir os eventos; pelo contrário, ele parece ser constantemente subjugado pelas tarefas com as quais se depara, o que, se seguirmos uma equação conveniente em que protagonismo necessariamente significa heroísmo, inicialmente limita o seu papel de personagem principal a um regime formal.

${ }^{17}$ Outras menções a suicídio por parte de Quéreas aparecem em 1.4.7, 1.5.2, 3.3.1, 3.5.6, 4.3.6, 4.4.10, 5.2.4-5, 5.10.6-9, 6.2.8-11. O que proponho aqui é que, para além do caráter patético (e da comicidade) que pode ser facilmente reconhecido nessas passagens, há um significado implicado nas cenas de tentativa de suicídio: uma incapacidade de enfrentamento, o que destoa do código épico clássico e instaura uma nova perspectiva sobre os heróis: o enfraquecimento e insularidade próprios de um personagem que ainda está assimilando o modus operandi que se espera dele. Em última análise, portanto, trabalho com os mesmos pressupostos de Lalanne (2014), que vê nos romances gregos uma construção das personae em conformidade com as expectativas modelares de cada gênero, o masculino e o feminino. 
Para entendermos melhor esse protagonismo narrativo que não encontra uma correspondência inicial nas ações de Jasão e Quéreas, é necessário examinar algumas de suas causas, dentre as quais destaco para o atual estudo: i) a ineficácia retórica e ii) a falta de controle sobre os seus sentimentos e os demais personagens.

\section{Ineficácia e falta de controle}

Na passagem há pouco aduzida de $Q \& C$, Quéreas é incapaz promover a sua culpa de modo convincente e o seu projeto, por impulsivo e pouco calculado que fosse (ou talvez justamente devido a esses fatores), é frustrado pela primazia judicial de Hermócrates. Essa não é a única passagem que apresenta uma defasagem entre a intenção de Quéreas e os modos pelos quais ele busca realizá-la. No terceiro livro, quando Quéreas traz Teron à Siracusa, a descrição que se faz do (proto-)herói é sintomática de sua inabilidade:

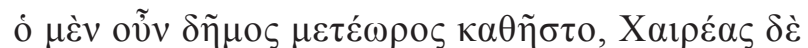

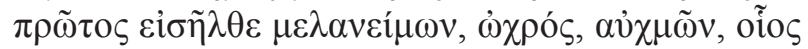

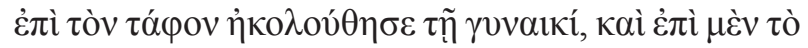

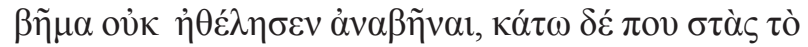

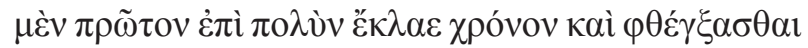

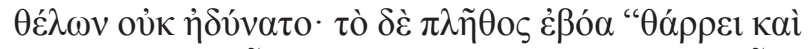

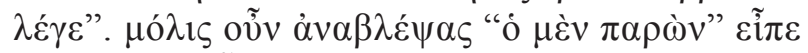

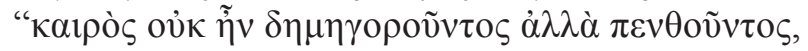

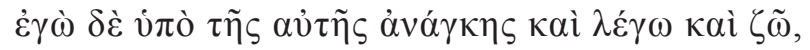

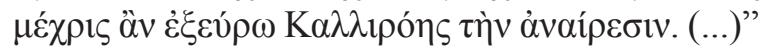

Enquanto o povo sentava-se em suspense, Quéreas foi o primeiro a entrar, vestido de preto, pálido, desmilinguido, como quando acompanhou sua mulher ao túmulo. Não quis subir à tribuna, mas, parado ali embaixo, primeiro chorou por muito tempo e, embora quisesse falar, não conseguia. A multidão gritava: "Coragem, fale!"' Com dificuldade levantou os olhos e disse: "A ocasião que ora se apresenta não era de discurso, mas de luto. Contudo, forçado pela necessidade, eu falo e me mantenho vivo até elucidar o desaparecimento do corpo de Calírroe. (...)" (3.4.56; grifos meus) 
O que vemos aqui não é a presença de uma retórica que busca o convencimento, parte essencial do ingresso na vida adulta masculina durante o período histórico retratado (TEMMERMAN, 2009, p. 260262), mas antes uma ineficácia que se traduz no aspecto físico e na dificuldade de Quéreas de se expressar com clareza, entregue que está às suas próprias emoções lutuosas. Complementarmente, mais adiante fica claro o insucesso de seu discurso público:

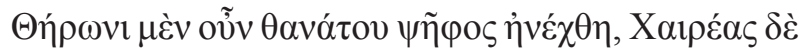

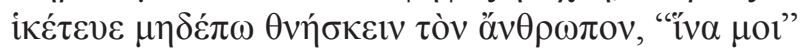

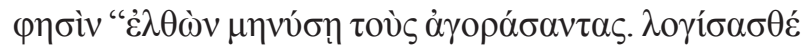

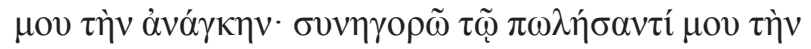

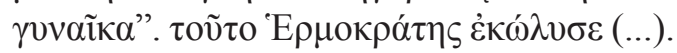

A pena de morte foi atribuída a Teron, mas Quéreas suplicou que não o matassem, para que, ele disse, "fosse comigo e revelasse a identidade dos compradores. Pensem no que sou constrangido a fazer. Devo argumentar em favor do vendedor da minha mulher". A isso Hermócrates opôs-se (...). (3.4.15 et seq.; grifos meus)

Seguindo o paradigma opositivo que Héracles representa a Jasão, Hermócrates serve como baliza e contraponto aos anseios de Quéreas. A vontade do protagonista não apresenta qualquer reflexo na realidade diegética: ela permanece reduzida à sua subjetividade, neutralizada, mais uma vez, em um locus que antecede o registro das ações e da efetividade em geral. Em suma, as suas palavras não possuem o valor no espaço público que mais tarde terão no sétimo e oitavo livros. ${ }^{18}$ Nem nesse discurso nem no discurso supracitado do primeiro livro, Quéreas obtém o sucesso ou o efeito desejados - em decorrência da sua inabilidade retórica, ele é facilmente superado por outros personagens (TEMMERMAN, 2014b, p. 87).

${ }_{18}$ Temmerman, 2009, p. 253; Temmerman, 2014b, p. 86, em que o autor nota que, durante os seis primeiros livros, Cáriton nos traz apenas dois discursos feitos por Quéreas (ambos apresentados aqui à guisa de argumento), ao passo que nos últimos dois livros, vemos sete discursos de Quéreas, o que Temmerman considera significativo. 
A ineficácia discursiva de Jasão é congênere à de Quéreas. No trecho já tratado em que vemos como ele se torna o líder do mínios, fica claro que a obtenção desse título não se deve à capacidade argumentativa do próprio Jasão, mas, na realidade, à de outro personagem, o seu contraponto heroico: Héracles. Com efeito, Héracles não é apenas força, mas também decisão. As já mencionadas reprimendas que Jasão recebe de Héracles e de Lico escavam ainda mais a discrepância entre o que é esperado de Jasão e o que ele efetivamente cumpre.

Mais adiante, ao dialogar com Fineu, Jasão, com boa vontade, tenta consolá-lo, ao que as suas palavras se demonstram inúteis:

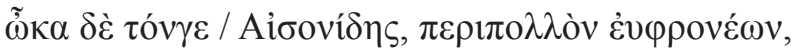

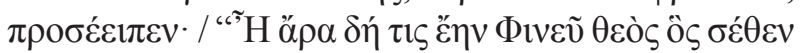

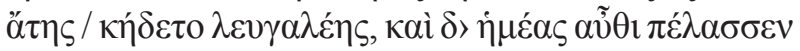

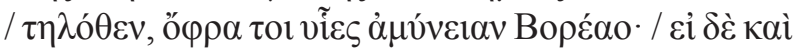

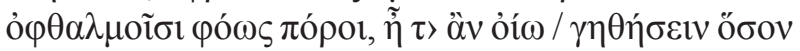

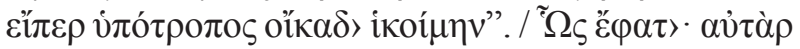

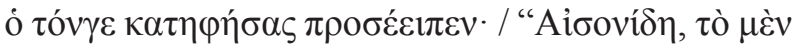

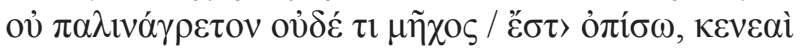

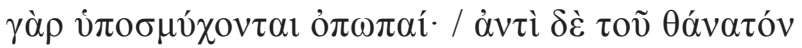

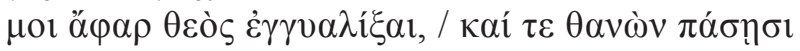

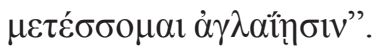

(...) Logo o Esonida, / de modo bastante prudente, disse-lhe: / "Certamente foi um deus, Fineu, que se preocupou / com tua triste ruína e nos trouxe de longe / para cá, para que os filhos de Bóreas te defendessem. / Se também lhe concedesse luz aos olhos, penso que certamente / alegrar-me-ia como se eu retornasse para casa". / Assim falou, mas ele melancólico the disse: / "Esonida, isto é irreparável e não há nenhum / remédio, pois minha visão vazia foi lentamente consumida. / Ao invés disso o deus me dispôs logo a morte, / e quando estiver morto estarei envolto em todo brilho". (2.436-47)

$\mathrm{O}$ vate reconhece a irreversibilidade de sua morte, mas Jasão tenta "remediá-la" sem qualquer efeito. É frisada aqui a sua ausência de poder frente àquilo que já estaria determinado. Diante desses e de outros 
momentos, o que pode ser constantemente frisado é a passividade de Jasão (BEYE, 1969, p. 54-55). Apolônio oferece o retrato de um herói amékhanos, incapaz de promover diferenças e efeitos na realidade diegética.

Outro aspecto a ser explorado é a ausência de controle que ambos os personagens exibem a respeito dos seus móbiles e dos demais personagens, fator esse que já foi explorado por outros autores. ${ }^{19}$ No episódio de Lemno, Jasão é constantemente ludibriado por Hipsípile a permanecer ali em virtude de uma justificativa dada por ela que não corresponde à realidade dos fatos (1.793-833). A hospitalidade oferecida pelas mulheres de Lemno é retratada essencialmente como um embuste (1.849-52), o que desvirtua os heróis da razão principal da viagem. Com efeito, a própria motivação da viagem é uma forma de engodo por parte de Pélias, pela qual Jasão se deixa levar (1.5-17). Enquanto é recebido pelos dolíones, Jasão narra os motivos da expedição, mas fica claramente expressa a sua incapacidade de reportar os eventos além do seu horizonte de consciência, naturalmente limitado ao aceite das prescrições de Pélias (1.980-4).

No caso de Quéreas, a falta de controle não se limita à sua própria esfera de atuação, mas tem logo uma repercussão negativa no seu entorno - se Jasão se sente prostrado ante as dificuldades, Quéreas, por vezes, comporta-se sem qualquer restrição. Consequência do ciúme, a sua reação explosiva, por exemplo, causa a morte aparente de sua esposa (1.4.12; cf. ainda 1.2.5-6, 1.5.4). Os seus sentimentos o consumem e o levam a ações irrefletidas, que amiúde são refreadas por outros personagens, como no seguinte trecho:

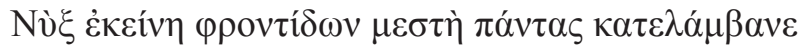

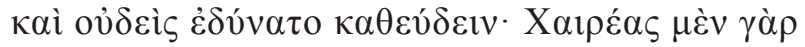

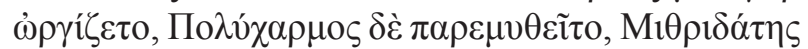

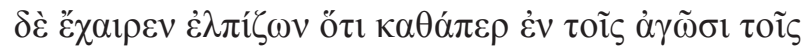

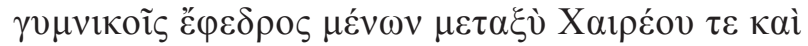

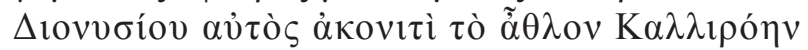

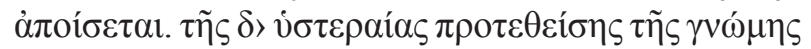

${ }^{19}$ Beye, 1969, p. 41: “Jason seems not to be master of his actions. He is swept along - no doubt unseeing and perhaps not caring - but part of the surge of events which he cannot control". Temmerman, 2009, p. 260: "At the beginning of the story, Chaereas is unable to achieve his desired aims through the use of speech. He lacks the rhetorical control required to persuade his audience. Moreover, in private conversation, he is controlled, and even manipulated and deceived, by his interlocutors". 


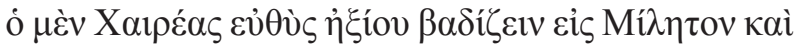

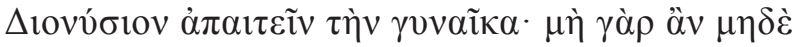

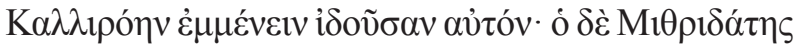

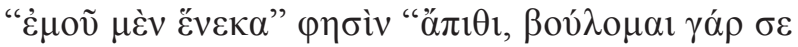

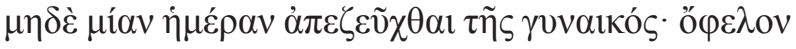
$\mu \eta \delta \dot{\varepsilon} \Sigma 1 \kappa \varepsilon \lambda i \alpha_{\alpha} \dot{\varepsilon} \xi \dot{\eta} \lambda \theta \varepsilon \tau \varepsilon, \mu \eta \delta \dot{\varepsilon} \sigma v v \dot{\varepsilon} \beta \eta \tau 1 \delta \varepsilon 1 v o ̀ v$

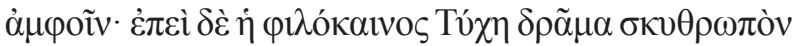

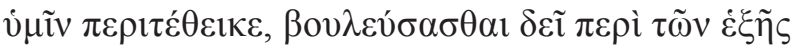
$\varphi \rho o v \imath \mu \omega ́ \tau \varepsilon \rho o v \cdot v \tilde{v} v \gamma \grave{\alpha} \rho \sigma \pi \varepsilon v ́ \delta \varepsilon 1 \varsigma \pi \alpha ́ \theta \varepsilon 1 \mu \tilde{\alpha} \lambda \lambda \mathrm{ov}$

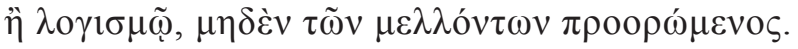

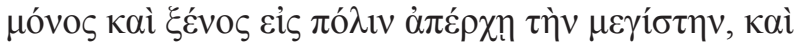

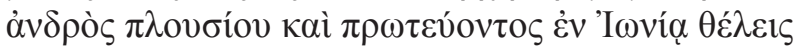

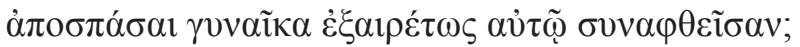

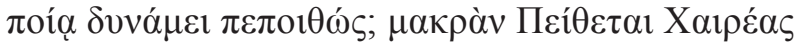

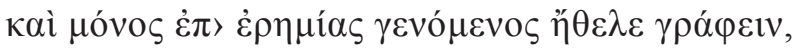

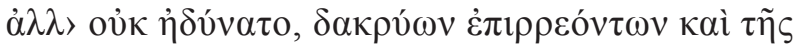

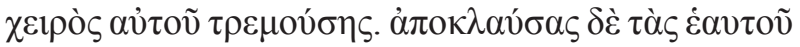

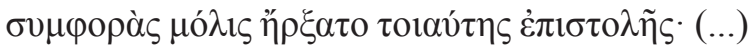

Aquela noite pegou todos em meio a preocupações e ninguém conseguia dormir. Enquanto Quéreas alimentava a raiva, Policarmo o consolava e Mitrídates comprazia-se com a esperança de que ele, como o reserva de Quéreas e Dionísio nos jogos por Calírroe, ficaria com o prêmio sem precisar lutar. No dia seguinte, quando se retomou o assunto, Quéreas julgou melhor ir de imediato a Mileto e reclamar sua mulher a Dionísio, pois Calírroe não ficaria lá, se o visse. Mitrídates disse: "No que depende de mim, parta! Não quero separá-lo um único dia de sua mulher. Tomara não tivessem deixado a Sicília, nem algo tão terrível tivesse acometido aos dois! Mas já que a Fortuna adora novidades e armou-lhes um drama triste, é preciso considerar sua sequência com a maior sensatez. Agora a sua pressa se deve mais à emoção do que à razão, sem que você anteveja nada do que está por vir. Você, sozinho e forasteiro, chega a uma cidade grande e quer arrebatar a esposa de um 
homem rico, o mais proeminente da Jônia, sendo que ela está notoriamente comprometida com ele? Com que poder conta convencê-lo? (...) Acho melhor você primeiro testar a sua mulher por meio de uma carta, se ela se recorda de você e quer abandonar Dionísio ou quer favorecer a casa daquele que a tiver desposado. Escreva uma carta para ela! Que ela fique aflita, em êxtase, que o busque e o chame! Eu cuidarei de despachar a carta. Vá e escreva!" Quéreas se deixou persuadir e estando sozinho, num lugar isolado, quis escrever, mas não conseguia, pois as lágrimas afluiam e as mãos tremiam. Depois de chorar por seus próprios infortúnios, foi com dificuldade que começou a seguinte carta (...). (4.4.1 et seq.; grifos meus)

Não obstante os interesses escusos de Mitríades, vê-se que ele, mesmo assim, funciona como um parâmetro de reflexão para Quéreas e, além disso, proporciona uma nova possibilidade de conduta, mais comedida, diante da qual Quéreas "se deixa persuadir". ${ }^{20}$ Quéreas demonstra, nessa passagem, dois aspectos essenciais de seu êthos inicial: ele é como que controlado pelas palavras de outro personagem e, antes disso, é retratado como que refém de seus impulsos irascíveis. ${ }^{21}$ Ambos aspectos representam, em um único ponto, a ausência de controle (de influências externas e internas) de Quéreas. Do mesmo modo, como já visto, as suas tentativas de suicídio também demonstram essa incapacidade de gerir os próprios sentimentos e a sua conduta reativa em geral: ao adotar tal resolução extrema, demonstra-se que Quéreas estaria inapto para conter as suas emoções (influência interna), assim como não apresentaria recursos para lidar com os eventos e provações narrados (influência externa).

\footnotetext{
${ }^{20}$ Temmerman (2014b, p. 94) observa que, antes da transformação pela qual Quéreas passa nos últimos dois livros, não só o seu poder militar, mas principalmente o seu poder retórico é subjugado por outros personagens, como Dionísio, Artaxerxes ou ainda, como no exemplo aqui aduzido, Mitríades.

${ }^{21}$ Para outros excertos que apresentam essas fraquezas de Quéreas, cf. Helms (1966, p. 29-37), em que, dentre várias facetas do herói, o autor seleciona momentos em que se evidenciam a sua "lack of resoluteness" (29-32), o fato de que ele é "easily deceived" (32), de que ele é "suspicious and jealous" (32-4) e "quick-tempered" (34-5). Para o ciúme como instabilidade de caráter, cf. Balot (1998, p. 151).
} 
De fato, Quéreas apresenta o que pode ser descrito como uma "exaggerated sensitivity and emotionalism" (HELMS, 1966, p. 28), o que funciona em flagrante contraste à passividade de Jasão. De qualquer forma, porém, tratam-se de dois modi operandi que operam aquém ou além da margem aceitável de ações: tanto o hipo- quanto o hiper- são duas formas resultativamente equivalentes de ineficácia e ausência de autocontrole. Esses momentos convergem em um único ponto: parece haver um tópos da incompatibilidade - seja entre intenção e expressão ou mesmo entre lógoi e érga - que parece resumir a condição de imaturidade heroica. O estágio inicial em que ambos os personagens se encontram é incompatível com as condições externas que exigem deles uma conduta propriamente heroica. Entretanto, esse não é o único aspecto explorado em Jasão e Quéreas, uma vez que, em certos momentos, no percorrer das jornadas de ambos, temos vislumbres do que cada um deles irá se tornar no final dessas obras.

\section{Potencial}

Os personagens só podem ser deficitários enquanto algo específico é esperado deles. Não existe deficit de caracterização sem uma expectativa (BALOT, 1998, p. 155). É nisso que se fundamentam as diversas leituras dos protagonistas tratados: Quéreas não é um Hermócrates; Jasão não é um Héracles. Todavia, se Cáriton e Apolônio estivessem interessados em escrever, respectivamente, um novo Hermócrates a partir de Quéreas e um novo Héracles a partir de Jasão, definitivamente o teriam feito desde o início, pois já dispunham dos modelos e dos expedientes para compô-los. Pelo contrário, na medida em que esses autores se detêm em fatores, por assim dizer, não formados dos heróis, vemos que não há nisso um defeito narrativo (por assimilação aos caracteres enunciados), mas antes um interesse narrativo: o interesse de entender e apresentar de que modo, no ventre da incapacidade, começam a ser engendrados os germes da capacidade. Nas Argonáuticas, é o potencial erótico, elemento inicialmente destoante no código heroico, que eventualmente destaca Jasão dos demais heróis e permite que ele conquiste o seu objetivo. ${ }^{22}$ Isso

${ }^{22}$ Lawall, 1966, p. 122-123. O início do terceiro livro explora etiologicamente esse tópos dos móbiles da sedução no plano divino, com a representação de Hera, Atena e Afrodite, que, por sua vez, expõe os caracteres de seu filho, Éros, o qual nem ela 
fica claro no episódio de Lemno (1.774-80) e ainda no sentimento que Jasão provoca em Hipsípile (1.786-91, 886-98). Mais um indício desse seu traço é explorado na écfrase de seu manto (1.721-73), ${ }^{23}$ ao que Beye nota:

No manto estão imagens apropriadas ao contexto do poema inteiro, ou seja, o conflito entre amor e guerra, ou, antes, amor na guerra e guerra no amor, tal como a imagem de Afrodite observando seu reflexo no escudo de Ares ou a competição de Hipodâmia em uma corrida, com amor e ódio claramente guerreando. ${ }^{24}$

Outro momento em que esse potencial fica evidente é durante a conversa entre o vidente Fineu e Jasão, que, frustrado com a sua própria inadequação, é aconselhado, então, a buscar, como amparo, o auxílio de Afrodite (2.416 et seq.). ${ }^{25}$ Basicamente, as provações pelas quais os mínios passam têm a função narrativa de revelarem essa latência em Jasão ${ }^{26} \mathrm{o}$ que resume o caráter desse herói já destacado pela crítica: em contraste com a tradição que o precede, Jasão é "le héros le plus humain" (VIAN, 2005, p. 51). A representação básica para se construir

mesma conseguiria domar (3.90-9). Com a partida de Éros para auxiliar o herói (3.15466), vemos a concomitante guinada da habilidade retórica do filho de Esão, que, ao discursar, logo recebe aprovação de todos os argonautas (3.171-95), o que indica o início da transformação de seu êthos.

${ }^{23} \mathrm{Cf}$. também logo em seguida o símile em que Jasão é comparado à estrela Héspero, relacionada ao tema amoroso/erótico, e o efeito que o herói causa nas demais moças da cidade (1.774-81). Noto de passagem que Quéreas também é descrito em certo momento como sendo "luzente como uma estrela" (1.1.5), o que pode engendrar mais leituras sobre a aproximação possível entre os dois heróis.

${ }^{24}$ Beye, 1969, p. 44: "On the cloak are images appropriate to the setting of the entire poem, that is the conflict between love and war, or rather love in war and war in love, such as the image of Aphrodite viewing her reflection in Ares' shield or the race contest of Hippodameia with love and hate clearly warring" (trad. P. B. Antunes). Vale frisar aqui que a descrição de "love in war and war in love" é tão adequada para as Argonáuticas quanto para $Q \& C$.

${ }_{25}$ Outras instâncias em que o elemento erótico aparece em Apolônio são aduzidas por Beye (1966, p. 48-55).

${ }^{26}$ Lawall, por exemplo, observa que: "It is in the first third of Book 3 that Jason shows the results of his education during the formative voyage" (LAWALL, 1966, p. 165; grifos meus). 
essa humanidade é a formação, cujo predicado primeiro é a deficiência, a carência do potencial atualizado. Apolônio retrabalha o legado homérico oferecendo uma tipificação heroica mais realista, passando de uma inferioridade inicial a um cumprimento do seu desígnio mediante qualidades próprias que não se pautam na bravura pré-existente dos seus companheiros. $^{27}$

O potencial de Quéreas, por sua vez, pode ser entrevisto em um trecho já comentado e que aduzo novamente: trata-se da passagem em que o herói é descrito como "um rapaz formoso, superior a todos, como os Aquiles, Nireu, Hipólito, Alcibíades que escultores e pintores retratam" (1.1.3). À primeira vista, pode-se imaginar que temos quatro paradigmas idealistas de uma beleza masculina, mas é possível também argumentarmos que esses paradigmas portariam facetas éticas específicas (TEMMERMAN, 2014a, p. 233-234). Se tomamos os eventos bélicos dos livros finais de $Q \& C$, por exemplo, percebemos que ali se efetiva um potencial marcial em Quéreas que poderia estar enunciado nessas figuras, como Aquiles e Alcibíades (SMITH, 2007, p. 199-244; BALOT, 1998, p. 156). Assim, no início do sétimo livro, lemos que o rei egípcio:

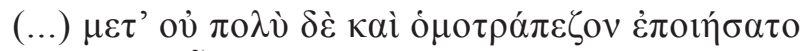

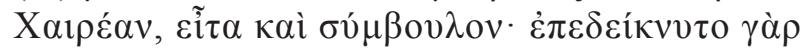

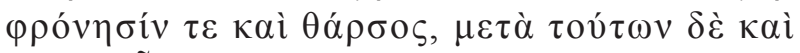

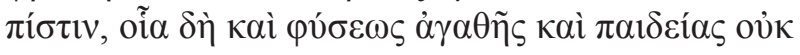

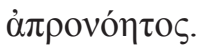

(...) fez de Quéreas seu comensal e, logo, conselheiro, pois dava provas de inteligência e coragem, além de inspirar confiança, já que não era desprovido também de boa índole e educação. (7.2.5; grifos meus)

Como que repentinamente, a narrativa elenca diversas qualidades de Quéreas que não pareciam estar retratadas nos momentos anteriores de sua jornada. O que temos aqui, porém, não é um desvio de um programa antes instituído de um herói incapacitado, mas a atualização de elementos germinais que culminam na identificação de phrónesis ou mesmo de thársos em Quéreas (TEMMERMAN, 2014b, p. 111-113). Se encararmos

${ }^{27}$ Vian, 2005, p. 52 (o crítico francês persiste na avaliação da "humanité" de Jasão à p. 61). 
$Q \& C$ como um Bildungsroman (BALOT, 1998, p. 139), essa descrição não deveria ser inesperada. Ressignificados os seus caracteres iniciais, $o$ protagonista cumpre o papel que é dele esperado (BALOT, 1998, p. 157). Sem evitar o fator erótico (i.e. a beleza) que permeia três dos personagens elencados (Nireu, Hipólito e Alcibíades), o que é explorado nos livros finais do romance não é necessariamente o potencial sedutor de Quéreas, como é o caso de Jasão, mas, sim, os seus momentos de grandeza em meio às batalhas de que faz parte, ou, ainda mais precisamente, a sua capacidade de liderança. Enquanto a sedução é algo explorado apenas inicialmente, o que logo enseja o casamento entre Quéreas e Calírroe, o resto do trajeto do protagonista masculino não parece mais repousar sobre esse fator. Se apenas a beleza fosse considerada, Aquiles dificilmente seria o melhor candidato para ser trazido como exemplum homérico. Disso, podemos pensar que há mais do que um único aspecto em direção ao qual os quatro personagens convergiriam. Talvez seja interessante avaliar quais outros traços eles apresentam e que cabem, evidentemente, a Quéreas. Nesse sentido, Temmerman argumenta que:

$\mathrm{Na}$ verdade, o tertium comparationis da assimilação de Quéreas aos quatro paradigmas é explicitamente apresentado pelo narrador como a beleza física, o que parece frisar uma leitura diretamente idealizante. (...) Por um lado, eu argumentaria, todos os quatro paradigmas funcionam não só como meros marcadores de sua aparência física, mas ainda como sementes implícitas da natureza de Quéreas (...). Os tertia comparationis implícitos, abordados por esses quatro paradigmas, portanto, são impetuosidade, castigo divino e fraqueza, respectivamente. Embora o narrador qualifique a similaridade entre Quéreas e as quatro figuras mitológicas se referindo à sua representação por escultores e pintores e, assim, explicitamente chamando a atenção do leitor para as similiaridades físicas entre Quéreas e seus paradigmas, a mensagem explícita expressa por tais paradigmas lida ominosamente com algumas características internas importantes. Na verdade, eles tocam em algumas das mais importantes cordas da caracterização 
de Quéreas, que o romance desenvolverá. Mais do que atribuir uma função idealizante a esses paradigmas, eu argumentaria que eles, de maneira implícita, põem em destaque aspectos realistas psicologicamente importantes de sua natureza. ${ }^{28}$

Se entendermos as comparações feitas em relação a Quéreas como sugere Temmerman, vemos, contudo, que nem todas elas seriam reveladoras do processo pelo qual Quéreas passaria, mas antes indícios também dos momentos deficitários em meio aos quais o herói se vê no estágio inicial de sua formação: "impetuosity", "divine punishment" e "weakness". Retomo, ainda assim, os casos de Aquiles e Alcibíades. Se, por um lado, eles podem apontar para passagens em que certos "defeitos" de Quéreas são entrevistos, por outro, esses dois personagens carregam também uma valência positiva, que só poderia ser corretamente avaliada em Quéreas se considerarmos os livros finais do romance. Com efeito, assumindo que a caracterização ambígua era um princípio recorrente nos romances antigos (TEMMERMAN, 2014a, p. 233), é possível, sim, imaginarmos que a citação de tais personagens não precisa se limitar a um único conceito. De fato, é o próprio Temmerman que dá a deixa para como podemos encarar Alcibíades: "The figure of Alcibiades may be proleptic of Chaereas' brilliant military leadership at the end of the novel". ${ }^{29}$ Há,

${ }^{28}$ Temmerman, 2014a, p. 233-234: "Indeed, the tertium comparationis of Chaereas' assimilation to the four paradigms is explicitly presented by the narrator as physical beauty, which seems to underscore a straightforwardly idealizing reading. (...) On the other hand, I would argue, all four paradigms function not only as mere markers of his physical appearance, but also as implicit seeds of Chaereas' character. (...) The implicit tertia comparationis addressed by these four paradigms, then, are impetuosity, divine punishment, and weakness, respectively. Although the narrator qualifies the similarity between Chaereas and the four mythological figures by referring to their representation by sculptors and painters, thus explicitly drawing the reader's attention to the physical similarities between Chaereas and his paradigms, the implicit message conveyed by these paradigms ominously deals with some important inner characteristics. In fact, they touch upon some of the most important strands of Chaereas' characterization that the novel will develop. Rather than attributing an idealizing function to these paradigms, I would argue that they implicitly highlight important psychologically realistic aspects of his character" (Trad. P. B. Antunes, grifos do autor).

${ }^{29}$ Temmerman, 2014a, p. 233; grifo meu. Como já apontei, o mesmo argumento é apresentado por Smith, 2007. 
portanto, a possibilidade de entendermos que i) a comparação com Aquiles não se dá apenas pelo quesito comum de sua fúria, consonante à demonstração de ciúmes que faz com que Quéreas desfira um golpe contra Calírroe, mas talvez que, em $Q \& C$, Aquiles designe um papel heroico, repito, de liderança, algo próprio do "melhor dos aqueus"; além disso, podemos notar que ii) Alcibíades representaria não apenas o fenômeno erótico, mas também o sucesso militar. Assim, ambos os personagens serviriam como uma prolepse do $\underline{\underline{e}}$ thos final do protagonista. ${ }^{30}$

O processo de maturação posterior, apresentado no final de $Q \& C$ e das Argonáuticas, equivale, em suma, à atualização dos potenciais heroicos preludiados sutilmente nas passagens analisadas. Se cada protagonista exibe um tipo final particular, com um resultado comparado praticamente quiástico, ambos se irmanam em uma mesma estrutura narrativa: um período ético embrionário e o seu desenvolvimento ao final da trama. Enquanto Jasão seria em um último momento (a) um "love hero" cuja jornada se inicia por (b) um pretexto, por assim dizer, épico; em Quéreas teríamos (b') um herói final propriamente militar cujo móbile inicial teria sido (a') o impulso erótico figurado em Calírroe. O meu argumento é de que, no que diz respeito aos conteúdos, aquilo que nas Argonáuticas é apresentado como motivo de jornada (épos) e resultado formativo do protagonista (éros) seria, em $Q \& C$, aproveitado inversamente: o motivo inicial seria erótico e o resultado ético seria épico-homérico.

\footnotetext{
${ }^{30}$ Tirante o fator da beleza, Nireu e Hipólito, por sua vez, poderiam indicar os momentos problemáticos iniciais de Quéreas: Nireu como sua faceta debilitada (descrito como um personagem inábil em $I l$. 2.675) e Hipólito encarnando o paradigma da inveja (TEMMERMAN, 2014a, p. 234). Sendo esse o caso, a relação que Cáriton estabelece de Quéreas com essas personagens pode ser um tanto irônica, enganosamente enaltecedora. A enumeratio não seria de quatro nomes que se diluem em um conceito comum, mas de dois pares contrastivos: Nireu e Hipólito de um lado, Aquiles e Alcibíades de outro. No entanto, não sigo a argumentação desses personagens a fundo por entender que, em última análise, o foco principal para o meu raciocínio está suficientemente representado em Aquiles e Alcibíades, uma vez que o valor desses dois não se encontra atualizado em Quéreas, do que se nota a argumentada defasagem entre a descrição do personagem e suas ações iniciais. É na percepção da lacuna entre uma e outra instância que desenvolvo a atual argumentação.
} 


\section{Conclusão}

A representação paradigmática de Quéreas e Jasão envolve uma tipificação que vai além dos ready made heroes da tradição homérica. O que vemos aqui é a complexificação do projeto heroico, com um desenvolvimento que visa a não apenas adotar o programa épico, mas concretizá-lo de um modo menos idealizado (TEMMERMAN, 2009, p. 262; TEMMERMAN, 2014a, p. 234) e mais elaborado (TEMMERMAN, 2014a, p. 231-232). Os momentos de fraqueza e introspecção compartilhados pelos dois heróis não denunciam uma caracterização fraca de cada um, mas, na verdade, um projeto de maturação ou ainda uma espécie de narrativa etiológica do êthos heroico. Assim como Jasão deve conquistar um protagonismo que só será efetivado, de fato, no final das Argonáuticas (LAWALL, 1966, p. 149), Quéreas deve passar por provações emocionais, militares e retóricas até tornar-se um herói nos últimos dois livros de $Q \& C$. Em ambos os personagens testemunhamos um projeto de formação heroica que envolve, como móbile $(Q \& C)$ ou como instrumento (Argonáuticas), o elemento erótico. De início, ambos apresentam um protagonismo meramente formal no que diz respeito às suas habilidades e reputação, mas logo vemos nos dois personagens um processo de aquisição de valor ou até mesmo da própria criação de protagonistas.

Talvez, portanto, seja possível propor o seguinte itinerário: enquanto, em um primeiro momento, Apolônio reconsidera o funcionamento do herói homérico, introduzindo nele hesitações e uma subjetividade que é trabalhada dentro da própria narrativa, Cáriton, em seguida, pode muito bem ter se valido dessa experiência inicial, que laceou as diretrizes de composição heroica. Sendo assim, ele retrabalhou ${ }^{31}$ uma fonte dupla: não apenas flertou com algo próximo do herói homérico (militar), que pode ser entendido como a representação feita de Quéreas nos dois livros finais de $Q \& C$, mas também observou

\footnotetext{
${ }^{31}$ O princípio de experimentação e adaptação de tipos de personagens era algo bastante recorrente dentro da tradição do romance antigo, cf. Temmerman (2014a, p. 231232): "The general observation by some that the open format of the novel encourages experimentation and development (...) seems to be confirmed by ancient novelistic adaptations of character types. Indeed, the novels tend not merely to adopt traditional character types but also to elaborate, vary, complicate, develop, or creatively enhance them. (...) In some instances, various character types are blended together into a single novelistic character".
} 
a possibilidade de ocupar-se da psique do próprio herói apoloniano, deslocando o papel de Éros na trama, que, agora, em vez de operar unicamente a favor do herói como divindade benfazeja, é também causa de desavenças. Outro desenvolvimento marcante de Jasão para Quéreas é a passividade do primeiro contrastada com a expressividade intensa do segundo, o que, enquanto diferença, não precisa significar necessariamente descontinuidade, podendo plausivelmente ser uma influência remanejada.

Ao demonstrar que os critérios de avaliação de ambos os personagens podem ser os mesmos - ou ao menos que esses heróis permitem um mesmo tipo de argumentação e leitura, o que sinaliza algum tipo de homologia entre eles -, espero ter apontado a possibilidade de as Argonáuticas terem de algum modo servido como referencial para a composição do romance caritoniano. ${ }^{32}$

\section{Referências}

BALOT, R. Foucault, Chariton, and the masculine self. Helios, Lubbock, V. 25, n. 2, p. 139-162, 1998.

BEYE, C. R. Jason as love-hero in Apollonios" "Argonautika". Greek, Roman and Byzantine Studies, Durham, v. 10, n. 1, p. 31-55, 1969.

HÄGG, T. The Novel in Antiquity. Oxford: Basil Blackwell, 1983.

HELMS, J. Character portrayal in the Romance of Chariton. The Hague: Mouton \& Co., 1966.

HOLZBERG, N. The Ancient Novel: an introduction. Trans. by Christine Jackson-Holzberg. London/New York: Routledge, 1995.

KONSTAN, D. The Greek Novel: sexual symmetry. In: KONSTAN, D. Sexual symmetry: love in the Ancient Novel and related genres. Princeton, New Jersey: Princeton University Press, 1994. p. 14-59.

LALANNE, S. Education as construction of gender roles in the Greek Novels. In: CUEVA, E.; BYRNE, S. (Org.). A Companion to the Ancient Novel. Oxford: Wiley Blackwell, 2014. p. 473-489.

\footnotetext{
${ }^{32}$ Agradeço as leituras e comentários de Adriane da Silva Duarte, Lucia Sano e do parecerista anônimo. Todos os problemas remanescentes no texto são exclusivamente de minha autoria.
} 
LAWALL, G. W. Apollonius' Argonautika: Jason as anti-hero. Yale Classical Studies, New Haven, v. 19, p. 121-169, 1966.

RODRIGUES JUNIOR, F. Áristos Argonaútōn: o heroísmo nas "Argonáuticas" de Apolônio de Rodes. 2010. 272 f. Tese (Doutorado em Letras Clássicas) - Faculdade de Filosofia, Letras e Ciências Humanas da Universidade de São Paulo, 2010.

SCHMELING, G. Callirhoe: God-like beauty and the making of a celebrity. In: HARRISON, S. et alii (Org.). Metaphor and the Ancient Novel. Groningen: Barkhuis Publishing \& Groningen University Library, 2005. p. 36-49.

SMITH, S. D. Greek identity and the Athenian past in Chariton: the Romance of Empire. Groningen: Barkhuis Publishing \& Groningen University Library, 2007.

TEMMERMAN, K. Chaereas revisited: rhetorical control in Chariton's "ideal" novel "Callirhoe". Classical Quarterly, Cambridge, v. 59, n. 1, p. 247-262, 2009.

TEMMERMAN, K. Characterization in the Ancient Novel. In: CUEVA, E.; BYRNE, S. (Org.). A Companion to the Ancient Novel. Oxford: Wiley Blackwell, 2014a. p. 231-243.

TEMMERMAN, K. Crafting Characters: heroes and heroines in the Ancient Greek Novel. Oxford: Oxford University Press, 2014b.

VIAN, F. IH $\Sigma \Omega N$ AMHXANE $\Omega N$. In: ACCORINTI, D. (Org.). L'épopée posthomérique: recueil d'études. Alessandria: Edizioni dell'Orso, 2005. p. 49-65. 